\title{
A Numerical Model for Radial Transport in the ELMO Bumpy Torus
}

\author{
E. F. Jaeger \\ C. L. Hedrick
}

\section{OAK RIDGE NATIONAL LABORATORY} OPERATED BY UNION CARBIDE CORPORATION · FOR THE DEPARTMENT OF ENERGY 


\section{DISCLAIMER}

This report was prepared as an account of work sponsored by an agency of the United States Government. Neither the United States Government nor any agency Thereof, nor any of their employees, makes any warranty, express or implied, or assumes any legal liability or responsibility for the accuracy, completeness, or usefulness of any information, apparatus, product, or process disclosed, or represents that its use would not infringe privately owned rights. Reference herein to any specific commercial product, process, or service by trade name, trademark, manufacturer, or otherwise does not necessarily constitute or imply its endorsement, recommendation, or favoring by the United States Government or any agency thereof. The views and opinions of authors expressed herein do not necessarily state or reflect those of the United States Government or any agency thereof. 


\section{DISCLAIMER}

Portions of this document may be illegible in electronic image products. Images are produced from the best available original document. 
Printed in the United States of America. Available from National Technical Information Service

U.S. Department of Commerce

5285 Port Royal Road, Springfield, Virginia 22161

Price: Printed Copy $\$ 4.50$; Microfiche $\$ 3.00$

This report was prepared as an account of work sponsored by an agency of the United States Government. Neither the United States Government nor any agency thereof, nor any of their employees, contractors, subcontractors, or their employees, makes any warranty, express or implied, nor assumes any legal liability or responsibility for any third party's use or the results of such use of any information, apparatus, product or process disclosed in this report, nor represents that its use by such third party would not infringe privately owned rights. 
ORNL/TM- 6013

Contract No. W-7405-eng-26

Fusion Energy Division

A NUMERICAL MODEL FOR RADIAL TRANSPORT

IN THE ELMO BUMPY TORUS

E. F. Jaeger and C. L. Hedrick

Date Published - November 1977

This report wotice

whepared as an eccount of work

United States United States Covemment. Neicher the

Energy, nor any of the United States Depertment of

contractors, subcontractors, or their employes, melir

any warranty, express or implied, or assumes, any les

lisbility of responsibility for the scrumey comple lega

or usefulness of any information, sppar completeness

process disclosed, or represents that its use produet or

infringe privately owmed rights. that its use would not

NOTICE This document contains information of a preliminary nature. It is subject to revision or correction and therefore does not represent a final report.

Prepared by the

OAK RIDGE NATIONAL LABORATORY

Oak Ridge, Tennessee 37830

operated by

UNION CARBIDE CORPORATION

for the

DEPARTMENT OF ENERGY 
ABSTRACT

Neutral and charged particle densities and temperatures are calculated as functions of radius for the toroidal plasma in the ELMO Bumpy Torus (EBT) experiment. Energy dependent ionization and chargeexchange rates, ambipolar diffusion, and self-consistent radial electric field profiles are included. Variation in magnetic field due to finite plasma pressure, effects of energetic electron rings, and transport due to drift waves and magnetic field errors are neglected. Diffusion is assumed to be neoclassical with enhanced losses at low collisionalities. The model repreduces many of the observed features of EBT operation in the quiescent toroidal (T) mode. The self-consistently calculated electric field is everywhere positive (not as in experiments) unless enhanced electron collisionality is included. Solutions for advanced EBT's are obtained and confinement parameters predicted. 


\section{INTRODUCTION}

In the ELMO Bumpy Torus (EBT) experiment, plasma is confined by a number of toroidally linked magnetic mirrors and is heated by microwaves. In the toroidal or $\mathrm{T}$-mode of operation, rings of hot electrons form in the midplane of each mirror with energies of a few hundred kilovolts. For sufficient microwave power, the diamagnetic plasma current of the electron rings is enough to reverse vacuum magnetic field gradients and pronisce an average minimum in the magnetic field that is required to stabilize a cuuler lut more donso toroidal plasma. The toroidal plasma of the T-mode discharge is characterized by relatively long lifetimes and a low fluctuation level. Because of this seemingly well-confined, quiet behavior, there is much interest in studying the toroidal plasma in EBT as a possible environment for controiled thermoniclear fusiun reactions. Huwever, to oxtrapolate the results of the current experiment to larger machines, a basic theory for particle and energy transport in the toroidal plasma is needed. Such theories have already been developed for alternate toroidal magnetic traps such as tokamaks [1] . In this paper we develop a time-dependent, one-dimensional radial transport model for the toroidal plasmu in EBT which is based on a series of moments of the bounce averaged drift kinetic equarton [2]. Quasi-charge neutrality is assumed to compute a self-consistent radial ambipolar electric field. Except as required for gross MHD stability, effects of the hot electron rings are ignored. Since it is not yet clear which process or combination of processes is most important in determining the transport rates in EBT, the model is developed in terms of a general set of diagonal and off diagonal transport coefficients. However, for 
the purpose of obtaining specific results here, we use transport rates based on classical and neoclassical calculations which are modified at low collisionalities to model collisionless transport processes.

Transport in bumpy torus type geometries has been the subject of some previous investigations [3-9]. However, radially resolved calculations with self-consistent electric fields have not previously been attempted. Kovrizhnykh [3] applies neoclassical theory to compute analytic expressions for particle and energy flux across the magnetic field in various toroidal magnetic systems. For the bumpy torus, Kovrizhnykh considers only the limit of very large radial electric fields where the results in general do not depend on the poloidal component of electric field. Spong and Harris [4] obtain numerical results for finite radial electric fields and no poloidal electric field. Hedrick et al. [5] apply Kovrizhnykh's results in a zerodimensional point model to derive analytic expressions for bulk densities and temperatures in the EBT toroidal plasma. They assume particle and energy diffusion times to be equal. Transport rates and confinement times have been predicted by Ikegami and Dandl [6] and Quon and Dand1 [7] based on magnetic field errors, and by Batchelor [8] and McBride [9] based on the theory of drift wave stability in EBT including trapped particle modes.

Calculations described in this paper extend the zero-dimensional point model of Hedrick et al. [5] to include radially resolved density and temperature profiles, energy dependent ionization and charge-exchange rates, distinct particle and energy diffusion times, a spatially resolved selfconsistent radial electric field, and a time varying self-consistent 
neutral density profile. Our results are thus applicable over a much wider range of plasma parameters than those of Ref...[5]. However, since we do not consider variation in magnetic fields due to finite plasma pressure, effects of energetic electron rings, or transport due to magnetic field errors and drift waves, and since we only crudely model effects of loss regions where electric and magnetic field drifts cancel (super banana particle orbits), it is not expected that our results will be applicable in all aspects to real EBT plasmas. Rather we regard this work as a step toward a complete transport model for EBT and similar axially asymmetric toroidal systems.

In Section 2 we derive the five transport equations used to describe the time-dependent behavior of charged and neutral particles in the presence of a self-consistent radial electric field. In Section 3, we discuss results of a numerical solution of these equations for parameters corresponding to the current experiment, EBT I, and the next generation experiment, EBT S. A simplified model in Section 4 assumes an ad hoc electric field, and results are compared to those found with the selfconsistent equations. EBT I data appear to be consistent with neoclassical transport if one assumes reasonable ad hoc electric fields of either sign. In Section 5 the self-consistent model is used to examine the effect of variations in plasma conditions such as (a) changes in the edge density of neutrals, (b) supplementary ion heating, and (c) enhanced electron collisionality. Self-consistently calculated electrlc fielus are generally positive (not as in experiments) unless enhunced electron collisionality is included. Calculations for EBT $S$ design parameters predict ion temperatures as high as $160 \mathrm{eV}$ and a product of density and energy confinement time of $6 \times 10^{11} \mathrm{sec} \mathrm{cm}-3$. 


\section{TRANSPORT EQUATIONS}

\subsection{Moments of the Drift Kinetic Equation}

We begin with the bounce averaged drift kinetic equation [2] for the distribution of guiding centers $f=f\left(r, \theta, v_{\perp}, v_{\|}, t\right)$

$$
\frac{\partial f}{\partial t}+\vec{v}_{D} \cdot \nabla f+\vec{A} \cdot \vec{v}_{v} f=C(f)
$$

where $\vec{v}_{D}$ is the guiding center drift velocity, and $C(f)^{\circ}$ is the collision integral. The acceleration $\vec{A}$ may be written

$$
\begin{aligned}
& A_{\perp}=\frac{B}{m v_{\perp}} \dot{\mu}+\frac{v_{\perp}}{2 B} \frac{\partial B}{\partial t}+\vec{v}_{D} \cdot \frac{v_{\perp}}{2 B} \nabla B \\
& A_{\|}=\frac{-B}{m v_{\|}} \dot{\mu}+\frac{\vec{v}_{D}}{v_{\|}} \cdot\left(\frac{e}{m} \vec{E}-\frac{v_{\perp}^{2}}{2 B} \nabla B\right)
\end{aligned}
$$

where $m$ is the mass, $e$ is the charge, $\mu$ is the magnetic moment, $\vec{E}$ is the electric field, and $v_{1}$ and $v_{\|}$are velocity components perpendicular and parallel to the magnetic field $B$, respectively. Choosing toroidal coordinates $\mathrm{r}$ and $\theta$ as in Fig. $1, \vec{v}_{\mathrm{D}}$ may be written

$$
\vec{v}_{D}=\left(v_{D y} \sin \theta+E_{\theta} / B\right) \hat{r}+\left(r \Omega+v_{D y} \cos \theta\right) \hat{\theta}
$$

where 


$$
\begin{aligned}
& \Omega=\Omega_{\nabla B}-E_{r} /(r B) \\
& v_{D y}=\frac{-v^{2}}{2 \omega_{c} R_{T}}\left(1+\frac{v_{\|}^{2}}{v^{2}}\right) .
\end{aligned}
$$

In Eqgs (3) and (4), we assume an axial magnetic field, $B=B_{z}=B_{o} / h$ where $h=1+r / R_{T} \cos \theta, \omega_{c}$ is the cyclotron frequency and $R_{T}$ is the major radius of the torus. The aximuthal drift frequency represented by $\Omega_{\nabla B}$ is due to mirror-like gradients and curvature in the magnetic field. It can be shown that the drift velocity and deceleration are in general related by the expression

$$
\nabla \cdot \vec{v}_{D}=-\nabla_{v} \cdot \vec{A}
$$

which for Hamiltonian systems is equivalent to lle equations of motion. Moments of the drift kinetic equation are derived by multiplying Eq. (1) by an arbitrary functionn $w$, integrating over velocity, and averaging over $\theta$. Using Eq. (5), we obtain

$$
\begin{gathered}
\frac{\partial}{\partial t}(n\langle\psi\rangle)-n\left\langle\frac{\partial \psi}{\partial t}\right\rangle+\nabla \cdot\left(n\left\langle\vec{v}_{D} \psi\right\rangle\right)-n\left\langle\vec{v}_{D} \cdot \nabla \psi\right\rangle-n\left\langle\vec{A} \cdot \nabla_{v} \psi\right\rangle \\
=\int \frac{h d \theta}{2 \pi} \int d^{3} \vec{v} \psi C(f)
\end{gathered}
$$

where $\langle\psi\rangle=\frac{1}{n} \int \frac{h d \theta}{2 \pi} d \stackrel{3}{v} \psi f$. Setting $\psi=1$ and $\psi=\frac{m}{2}\left(v_{\perp}^{2}+v_{\|}{ }^{2}\right)$ in. Eq. (6) leads to the equations for particle and energy balance for the $j^{\text {th }}$ species, 


$$
\begin{aligned}
\frac{\partial n_{j}}{\partial t}+\nabla \cdot \vec{\Gamma}_{j} & =v_{i} n_{j} \\
\frac{\partial}{\partial t}\left(\frac{3}{2} n_{j} k T_{j}\right)+\nabla \cdot \vec{Q}_{j} & \\
& =e_{j} \vec{\Gamma}_{j} \cdot \vec{E}+n_{j} k T_{j} \frac{1}{B} \frac{\partial B}{\partial t}+\int \frac{h d \theta}{2 \pi} \int d \stackrel{3 \rightarrow}{\frac{m_{j}}{2}} v^{2} C\left(f_{j}\right)
\end{aligned}
$$

where $v^{2} \equiv v_{\perp}^{2}+v_{\|}^{2}, e_{j}$ is the charge, $k$ is Boltzmann's constant, $v_{i}$ is the ionization rate, and the particle and energy densities are defined respectively,

$$
\begin{aligned}
& n_{j}=\int \frac{h d \dot{\theta}}{2 \pi} \int d^{3} \vec{v} f_{j} \\
& \frac{3}{2} n_{j} k T_{j}=n_{j}\left\langle\frac{m_{j}}{2} v^{2}\right\rangle=\int \frac{h d \theta}{2 \pi} \int d^{3} \vec{v}^{\frac{m}{2}} v^{2} f_{j}
\end{aligned}
$$

The particle and energy fluxes are defined respectively,

$$
\begin{aligned}
& \vec{\Gamma}_{j}=n_{j}\left\langle\vec{v}_{D j}\right\rangle=\int \frac{h d \theta}{2 \pi} \int d^{3} \vec{v}^{\vec{v}_{D j}} f_{j} \\
& \vec{Q}_{j}=n_{j}\left\langle\vec{v}_{D j} \frac{m_{j}}{2} v^{2}\right\rangle=\int \frac{h d \theta}{2 \pi} \int d^{3} \vec{v}^{\frac{m_{j}}{2}} v^{2} \vec{v}_{D j} f_{j}
\end{aligned}
$$

In Eqs (8) and (9), $\frac{3}{2} \mathrm{n}_{j} \mathrm{kT}_{j}$ includes both the random and directed energy density and $\vec{Q}_{j}$ includes both the conductive and convective heat flow.

Results of neoclassical transport theory for axially asymmetric toroidal systems $[3,4]$ give the radial component of the particle and energy fluxes in Eq. (9) as 


$$
\begin{aligned}
& \Gamma_{j, r}=-D_{n j} \frac{\partial n_{j}}{\partial r}-D_{T j} \frac{\partial T}{\partial r}+n_{j} \mu_{j} E_{r} \\
& Q_{j, r}=-K_{n j} \frac{\partial n_{j}}{\partial r}-K_{T j} \frac{\partial T}{\partial r}+n_{j} ! ! T_{j} E_{r}
\end{aligned}
$$

where

$$
\begin{aligned}
& \mu_{j}=\frac{e_{j}}{k T_{j}} D_{n j} \\
& \mu_{T j}=\frac{e_{j}}{k T_{j}} K_{n j} .
\end{aligned}
$$

Tlie moment cquatione for an arhitrary species given by $\mathrm{E} 4$. (7) may be simplified to describe toroidal plasma containing ions and electrons. In the collision term on the right of $\mathrm{kq}$. (7b), we include the energy exchange rate between iuns and electrons,

$$
Q_{e i}=3 n v_{e i} \frac{m_{e}}{m_{i}}\left(k T_{e}-k T_{i}\right)
$$

and energy gain and loss rates due to ionizing and charge-exchange collisions. In Eq. (12), $\nu_{e i}$ is the electruntion collision frequency. Energy loss by line radiation of impurity atoms, which are excited by inelastic collisions with electrons, is found to be small for current density estimates of low charge state impurities in EBT [10]. 
We assume quasi-charge neutrality, i.e. $\mathrm{n}_{\mathrm{e}} \approx \mathrm{n}_{\mathrm{i}}$ and define $\mathrm{n} \equiv \mathrm{n}_{\mathrm{e}} \approx \mathrm{n}_{\mathrm{i}}$. Noting that equal radial fluxes of ions and electrons are required to maintain charge neutrality $\left(\Gamma_{r} \equiv \Gamma_{e, r}=\Gamma_{i, r}\right)$, we write just one equation for the conservation of ions and electrons and separate equations for energy conservation,

$$
\begin{aligned}
& \frac{\partial \mathrm{n}}{\partial t}=\mathrm{n}_{\mathrm{o}}\langle\sigma v\rangle_{i} \mathrm{n}-\frac{1}{\mathrm{r}} \frac{\partial}{\partial \mathrm{r}}\left(\mathrm{r} \Gamma_{\mathrm{r}}\right) \\
& \frac{\partial}{\partial t}\left(\frac{3}{2} n k T_{i}\right)=Q_{e i}-\frac{1}{r} \frac{\partial}{\partial r}\left(r Q_{i r}\right)-n_{o}\langle\sigma v\rangle_{c x} \frac{3}{2} n k\left(T_{i}-T_{o}\right) \\
& +e \Gamma_{i r} E_{r}+n_{o}\langle\sigma v\rangle_{i} \frac{3}{2} n k T_{o} \\
& \frac{\partial}{\partial t}\left(\frac{3}{2} \mathrm{nkT}_{e}\right)=2 \mathrm{~m}_{\mathrm{e}} \mathrm{n}\left\langle\mathrm{D}_{\dot{\mu}}\right\rangle-\frac{1}{\mathrm{r}} \frac{\partial}{\partial r}\left(r Q_{e r}\right)-Q_{e i}-n_{o}\langle\sigma v\rangle_{i} \mathrm{nE}_{I}-e \Gamma_{e r} E_{r}
\end{aligned}
$$

where we have assumed $\partial B / \partial t=0$. Only the radial dependence has been kept since axial and azimuthal uniformity has been assumed. The ionization rate $\nu_{i}$ is represented as $n_{0}\langle\sigma v\rangle_{i}$ where $n_{0}$ is the neutral density, and $n_{0}\langle\sigma \nu\rangle_{c x}$ represents the rate of charge exchange between ions and neutrals. The ionization energy of atomic hydrogen is $E_{I}=13.5 \mathrm{eV}$ and $T_{0}$ represents the neutral temperature.

The first term on the right side of Eq. (13c) represents the bulk microwave power source to electrons at the fundamental cyclotron resonance. $\left\langle D_{\mu}\right\rangle$ is the resulting effective diffusion coefficient in velocity space [11], 


$$
\left\langle D_{\mu}\right\rangle=\frac{\pi e^{2}}{n(r) m_{e}^{2}}\left\{\frac{n\left|E_{1}\right|^{2}}{L d \omega_{c} / d s}\right\}_{\omega_{c}(s)=\omega_{\mu}}
$$

where $n(r)$ is the field line averaged plasma density; $\left|E_{1}\right|$ is the complex microwave electric field amplitude perpendicular to $B$, and $L$ is the separation in $z$ between resonance zones. The quantity in brackets is to bc cvaluatod at a position, s, along the field line such that $\omega_{c}(s)=w_{\mu}$ where $\omega_{\mu}$ is the microwave frequency. Adopting a model bumpy cylinder magnetic field, the only.unknown in Eq. (14) is the microwave field amplitude $\left|E_{1}\right|$. Assuming a spatial profile for $\left|E_{1}\right|$, its magnitude can be determined by integrating the power density, $2 \mathrm{~m}_{\mathrm{e}} \mathrm{n}\left\langle u_{\mu}\right\rangle$, over the plasma volume and equating the result to the total power deposited in the toroidal component as estimated experimentally. For results given here, $\left|E_{\perp}\right|$ is assumed uniform in space, and $20 \%$ of the total microwave power is assumed absorbed by the toroidal plasma in EBT I and EBT S. Because of the large electron thermal conductivity, we find the results relatively insensitive to the particular microwave electric field profile chosen.

\subsection{Ambipolar Assumption and Diffusion Rates}

We define ambipolar diffusion coefficients in the usual way by equating radial particle fluxes from Eq. (10) for ions and electrons. After some rearrangement this yields,

$$
E_{r}=\frac{D_{n i}-D_{n e}}{\mu_{i}-\mu_{e}} \frac{1}{n} \frac{\partial n}{\partial r}+\frac{D_{T i} \frac{\partial T}{\partial r}-D_{T e} \frac{\partial T}{\partial r}}{n\left(\mu_{i}-\mu_{e}\right)}
$$


where the transport coefficients in general may depend on the electric field. Substituting Eq. (15) into Eq. (10) yields for the particle and energy fluxes

$$
\begin{aligned}
& \Gamma_{r}=-D_{n}^{a} \frac{\partial n}{\partial r}-D_{T e}^{a} \frac{\partial T_{e}}{\partial r}-D_{T i}^{a} \frac{\partial T_{i}}{\partial r} \\
& Q_{i r}=-K_{n i}^{a} \frac{\partial n}{\partial r}-K_{T i 1}^{a} \frac{\partial T_{i}}{\partial r}-K_{T i 2}^{a} \frac{\partial T_{e}}{\partial r} \\
& Q_{e r}=-K_{n e}^{a} \frac{\partial n}{\partial r}-K_{T e 1}^{a} \frac{\partial T_{e}}{\partial r}-K_{T e 2}^{a} \frac{\partial T_{i}}{\partial r}
\end{aligned}
$$

where the superscript "a" denotes the ambipolar rates defined as:

$$
\begin{array}{ll}
D_{n}^{a}=\frac{\mu_{i} D_{n e}-\mu_{e} D_{n i}}{\mu_{i}-\mu_{e}} ; & K_{n i}^{a}=K_{n i}-\mu_{T i} \frac{D_{n i}-D_{n e}}{\mu_{i}-\mu_{e}} \\
D_{T e}^{a}=\frac{\mu_{i} D_{T e}}{\mu_{i}-\mu_{e}} ; & K_{T i 1}^{a}=K_{T i}-\frac{\mu_{T i} D_{T i}}{\mu_{i}-\mu_{e}} \\
D_{T i}^{a}=\frac{-\mu_{e} D_{T i}}{\mu_{i}-\mu_{e}} ; & K_{T i 2}^{a}=\frac{\mu_{T i} D_{T e}}{\mu_{i}-\mu_{e}}
\end{array}
$$

$$
\begin{aligned}
& \mathrm{K}_{\mathrm{ne}}^{\mathrm{a}}=\mathrm{K}_{\mathrm{ne}}-\mu_{\mathrm{Te}} \frac{\mathrm{D}_{\mathrm{ni}}-\mathrm{D}_{\mathrm{ne}}}{\dot{\mu}_{\mathrm{i}}-\mu_{\mathrm{e}}} \\
& \mathrm{K}_{\mathrm{Te} 1}^{\mathrm{a}}=\mathrm{K}_{\mathrm{Te}}+\frac{\mu_{\mathrm{Te}} \mathrm{D}_{\mathrm{Te}}}{\mu_{\mathrm{i}}-\mu_{\mathrm{e}}} \\
& \mathrm{K}_{\mathrm{Te} 2}^{\mathrm{a}}=-\frac{\mu_{\mathrm{Te}} \mathrm{D}_{\mathrm{Ti}}}{\mu_{\mathrm{i}}-\mu_{\mathrm{e}}}
\end{aligned}
$$


We note for example that in the limit $\mu_{e} \gg \mu_{i}$, Eq. (17) gives $D_{n}^{a} \approx D_{n i}\left(1+T_{e} / T_{i}\right)$. Therefore, particle diffusion is dominated by the slower species, in this case the ions, while the faster electrons are electrostatically confined.

By writing the electric field and particle and energy fluxes as in Eqs (15) and (16), and substituting into Eq. (13), we eliminate the explicit linear dependence on the electric field from the final set of particle and energy balances which become

$$
\begin{aligned}
& \frac{\partial n}{\partial t}=n_{0}\langle\sigma v\rangle_{i} n+\frac{1}{r} \frac{\partial}{\partial r}\left(r D_{n}^{a} \frac{\partial n}{\partial r}+r D_{T e}^{a} \frac{\partial T}{\partial r}+r D_{T i}^{a} \frac{\partial T_{i}}{\partial r}\right) \\
& \frac{\partial}{\partial t}\left(\frac{3}{2} n k T_{i}\right)=\frac{1}{r} \frac{\partial}{\partial r}\left(r K_{n i}^{a} \frac{\partial n}{\partial r}+r K_{T i 1}^{a} \frac{\partial T_{i}}{\partial r}+r K_{T i 2}^{a} \frac{\partial T}{\partial r}\right)-\frac{e}{n\left(\mu_{i}-\mu_{e}\right)} \\
& x\left(D_{n}^{a} \frac{\partial n}{\partial r}+D_{T e}^{a} \frac{\partial T_{e}}{\partial r}+D_{T i}^{a} \frac{\partial T_{i}}{\partial r}\right)\left[\left(D_{n i}-D_{n \theta}\right) \frac{\partial n}{\partial r}+D_{T i} \frac{\partial T_{i}}{\partial r}\right. \\
& \left.-D_{T e} \frac{\partial T}{\partial r}\right]+Q_{\Delta}+n_{o}\langle\sigma v\rangle_{i} \frac{3}{2} n_{k T}-\ddot{n}_{o}\langle\sigma v\rangle_{c x} \frac{3}{2} n k\left(\mathrm{~T}_{i}-\mathrm{l}_{0}\right) \\
& \frac{\partial}{\partial t}\left(\frac{3}{2} n k T_{e}\right)=\frac{1}{r} \frac{\partial}{\partial r}\left(r K_{n e}^{a} \frac{\partial n}{\partial r}+r K_{T e 1}^{a} \frac{\partial T_{e}}{\partial r}+r K_{T e 2}^{a} \frac{\partial T_{i}}{\partial \underline{r}}\right)+\frac{e}{n\left(\mu_{i}-\mu_{e}\right)} \\
& x\left(D_{n}^{a} \frac{\partial n}{\partial r}+D_{T e}^{a} \frac{\partial T}{\partial r}+D_{T i}^{a} \frac{\partial T}{\partial r}\right)\left[\left(D_{n i}-D_{n e}\right) \frac{\partial n}{\partial r}+D_{T i} \frac{\partial T_{i}}{\partial r}\right. \\
& \left.-D_{T e} \frac{\partial T_{e}}{\partial r}\right]-Q_{\Delta}-n_{o}\langle\sigma v\rangle_{i}{n L_{I}}+2 m_{e} n\left\langle D_{\mu}\right\rangle
\end{aligned}
$$




\subsection{Electric Field Equation}

The ambipolar diffusion coefficients given in Eq. (17) are defined as a matter of convenience to eliminate the linear dependence on the ambipolar field from the particle and energy balances in Eq. (18). When the transport coefficients themselves depend on the electric field in a nonlinear way as they do in EBT, electron and ion fluxes are still not necessarily equal. In this case we solve an additional equation for the time-dependent electric field. From Ampere's law we have

$$
\frac{\partial \vec{D}}{\partial t}=-\vec{J}+\nabla \times \vec{H}
$$

where $\vec{D}=\underset{\approx}{\varepsilon \vec{E}}$ and $\underset{\approx}{\vec{B}}=\underset{\approx}{\mu \vec{H}}$ where $\underset{\approx}{\varepsilon}$ and $\underset{\approx}{\underset{\sim}{\mu}}$ are the permittivity and permeability tensors. The current density $\vec{J}$ includes a collisional part due to the diffusion flux, a collisionless part due to plasma polarization and waves, and an equilibrium part due to diamagnetic drifts. Since the magnetic equilibrium is determined on a time scale very much faster than the diffusion time scale considered here, we take it to be given. In principle, at the end of the diffusion calculation, the magnetic field can be recomputed and the diffusion solution repeated until convergence is achieved. Writing the radial component of the collisional current density as $\mathrm{J}_{\mathrm{r}}=\mathrm{e}\left(\Gamma_{\mathrm{ir}}-\Gamma_{\text {er }}\right)$, assuming $\mathrm{H}_{\theta}=0$, and making use of Eq. (10), the radial component of Ampere's law, when averaged over $\theta$, becomes

$$
\begin{aligned}
\frac{\varepsilon_{1}}{e} \frac{\partial E_{r}}{\partial t} & =\Gamma_{e r}-\Gamma_{i r} \\
& =\left[\left(D_{n i}-D_{n e}\right) \frac{\partial n}{\partial r}+D_{\text {I'i }} \frac{\partial T}{\partial r}-D_{T e} \frac{\partial T}{\partial r}\right]-n\left(\mu_{i}-\mu_{e}\right) E_{r}
\end{aligned}
$$


which reduces to $\mathrm{Eq}$. (15) in steady state. We note that the equilibrium currents (in the $\theta$ direction) do not enter this equation, and the collisionless currents, due to plasma polarization, enter through the perpendicular plasma dielectric, $\varepsilon_{1}=\varepsilon_{o}\left(1+\omega_{p i}{ }^{2} / \omega_{c i}{ }^{2}+\omega_{p e}{ }^{2} / \omega_{c e}{ }^{2}\right)$ where $\omega_{p j}$ is the plasma frequency, $\sqrt{n_{j} e_{j}^{2} / \varepsilon_{0} m_{j}} \cdot$ By $E_{r}$ in Eqs (19) and (15), we mean the azimuthally averaged radial electric field

$$
E_{1}(r)=\int \frac{h d \theta}{2 \pi} E_{r}(r, \theta)
$$

\section{$2.4 \quad$ Neutral Transport Mode1}

We assume that the neutral gas adjusts instantaneously to changes in the plasma parameters and write a stationary kinetic equation for the neutral distribution $f_{0}$ at each time

$$
\vec{v} \cdot \nabla f_{0}=-n_{e}\langle\sigma v\rangle_{i} f_{0}+\langle\sigma v\rangle_{c x}\left(n_{0} f_{i}^{M a x}-n_{i} f_{0}\right)
$$

The first term on the right represents a loss of neutrals due to ionization. 'The second term represents a net gain in neutral energy due to charge exchange where the charge-exchange neutrals are assumed born as a Maxwellian velocity distribution $f_{i}^{M a x}$ with the temperature of the ions. Assuming plane slab geometry and two groups of neutrals, one hot and one cold, Eq. (20) is.solved using the Oak Ridge neutral transport code [12] for the neutral density $n_{0}$ and neutral temperature $T_{0} \cdot$ Boundary conditions used are equivalent to a delta-function isotropic source of cold neutrals 
at the edge with energy $E_{o}$ and density $n_{o, e d g e}$

\subsection{Transport Coefficients}

Eqs (18) - (19) form a closed set which can be solved for $n, T_{e}, T_{i}$, $E_{r}, n_{0}$, and $T_{0}$. The functions $D_{n j}, D_{T j}, \mu_{j}, K_{n j}, K_{T j}$, and $\mu_{T j}$ used in the solution are taken from the neoclassical transport coefficient calculations of Refs [3-4] for a bumpy torus with closed magnetic field lines. In the limit of large radial electric field treated by Kovrizhnykh [3], small poloidal electric fields $E_{\theta}$ do not affect the magnitude of particle and energy fluxes, and the diffusion rates take the particularly simple form [3],

$$
\begin{array}{ll}
D_{n j}=\frac{v_{o j}^{2}}{24} \frac{\nu_{j}}{v_{j}^{2}+\Omega_{j}^{2}} & K_{n j}=\frac{7}{2} k T_{j} D_{n j} \\
D_{T j}=\frac{2 n_{j}}{T_{j}} D_{n j} & K_{T j}=\frac{101}{2} k_{j} \cdot D_{n j} \\
\mu_{j}=\frac{e_{j}}{k T_{j}} D_{n j} & \mu_{T j}=\frac{e_{j}}{k T_{j}} K_{n j}
\end{array}
$$

where $v_{o j}=2 k T_{j} /\left(m_{j} \omega_{c j} R_{T}\right)$ is the average drift. velocity due to toroidal curvature and $\nu_{j}=v_{j n}+v_{j e}+v_{j i}$ is the effective collision frequency where

$$
\nu_{e i}=\left(\frac{e_{i}}{e_{j}}\right)^{2} \nu_{e e} ; \nu_{i e}=\frac{m_{e}}{m_{i}} \nu_{e i} ; \nu_{j j}=\frac{e_{j}^{4} n_{j} \ell n \Lambda}{25.8 \sqrt{\pi \varepsilon_{o}^{2} m_{j}{ }^{1 / 2}\left(k T_{j}\right)^{3 / 2}}}
$$


and $\Lambda=12 \pi\left(\varepsilon_{\mathrm{o}} \mathrm{kT}_{\mathrm{e}} / \mathrm{e}^{2}\right)^{3 / 2} / \mathrm{n}_{\mathrm{e}}^{1 / 2}$. The transport coefficients in Eq. (2l) result from a direct solution of Eq. (1) where the gyromotion of the particles has been averaged out, and hence they do not include classical diffusion. We therefore add to these coefficients diffusion rates corresponding to the classical fluxes [3]

$$
\begin{aligned}
& \Gamma_{j, c}=\frac{\nu_{j n}}{m_{j} \omega_{j}^{2}}\left(-\nabla_{\perp} p_{j}+e_{j} n_{j} E_{1}\right)=\frac{\nu_{e i} \nabla_{\perp} p}{m_{e} \omega_{e}^{2}} \\
& Q_{j, c}=\frac{5}{2} k^{\prime} I_{j}\left(\Gamma_{j, c}-\frac{\nu_{j}}{m_{j} \omega_{j}^{2}} \mu_{j} \nabla_{\perp} k T_{j}\right)
\end{aligned}
$$

where $\dot{p}=p_{e}+p_{i}$ and $p_{j}=n_{j} k T_{j}$. In all cases considcrod, tho claesical rates are negligible compared to those given in Eq. (21).

It will be noticed that in the collisionless limit $\left(\nu_{j} / \Omega_{j} \ll 1\right)$, the diffusion coefficients of $\mathrm{Eq}$. (21) become arbitrarily small. This leads to difficulties in the self-consistent solution of Eqs (18) and (19) which result in arbitrarily large electric fields and steep gradients. Therefore, in order to model enhanced losses at low collisionalities due to drift waves and trapped particle effects, we multiply the rates in Eq. (21) by a factor $\left(1+\alpha{ }^{2} / \nu_{j}^{*}\right)$ where $v_{j}^{*}=\nu_{j} / \Omega_{j}$. For the results given in Sections 3 and 4 , we have taken $\alpha=0.2$. We note that inclusion of such enhanced losses yields more conservative estimates of plasma parameters than would otherwise be obtained, since i.t effectively decreases particle and energy lifetimes in the collisionless regime.

Finally, we comment on the validity of the assumptions which lead to the transport rates in Eq. (21). In particular, the assumption of a 
nearly Maxwellian velocity distribution [3,4] may be a poor one for electrons in EBT. Microwaves modify the distribution function by enhancing the high energy anisotropic tail which appears as the hot electron annulus in the experiment. Also, in the presence of a selfconsistent electric field, a loss region exists for the faster diffusing species in which a cancellation of poloidal drifts occurs. This can cause as much as an order of magnitude increase in transport rates for particles with thermal energies on the order of the electric potential [4]. In this case, the large electric field limit is clearly not applicable and even small poloidal electric fields can significantly affect particle and energy fluxes [3].

\section{RESULTS OBTAINED WITH A SELF-CONSISTENT ELECTRIC FIELD}

\subsection{Numerical Procedure}

The equations derived in the previous section have been applied to hydrogen plasma with parameters corresponding to EBT I and EBT S. The ambipolar diffusion equations given by Eq. (18) are solved in time using a Crank-Nicholson implicit scheme [13] with a spatial mesh of 50 points. A predictor-corrector step is used to treat nonlinear coefficients in the equations. The maximum possible time step on the diffusion time scale is limited by the nonlinearity in Eq. (18) and is typically $\Delta t_{\mathrm{D}} \approx 0.05 \mathrm{msec}$ for EBT I and EBT S. By contrast, the time scale for the electric field variation, as given by $\mathrm{Eq}$. (19) is on the order of $\Delta t_{E} \approx \frac{\lambda_{\mathrm{De}}{ }^{2}}{\mathrm{D}_{\mathrm{ne}}} \frac{\omega_{\mathrm{pi}}{ }^{2}}{\omega_{\mathrm{ci}}{ }^{2}} \approx 10^{-6}-10^{-5}$ sec where $\lambda_{D e}$ is the electron debye length. Hence the electric field adjusts very rapidly with respect to the plasma parameters. Therefore, after each time step on the diffusion time scale of Eq. (18), we follow Eq. (19) for a sufficient number of time steps (i.e. 10-50) to ensure that 
an approximate steady-state electric field has been calculated consistent with the plasma parameters for that time.

\subsection{Comparison to EBT I Data}

Figure 2 shows solutions to Eqs (18)-(21) for typical EBT I parameters, i.e. 24 mirror sectors with a plasma radius $a=10 \mathrm{~cm}$, a major radius $\mathrm{R}_{\mathrm{T}}=150 \mathrm{~cm}$, resonant magnetic field $\mathrm{B}_{\mathrm{O}}=6.4 \mathrm{kG}$, and total microwave power $55 \mathrm{~kW}$ with $20 \%$ of this (or $11 \mathrm{~kW}$ ) deposited in the toroidal core plasma. At the plasma edge $(r=a)$ we assume conditions characteristic of the cold surface plasma in ËBT I, $n=3 \times 10^{11} \mathrm{~cm}^{-3}$ with $\mathrm{kT}_{\mathrm{e}}=\mathrm{kT}_{\mathrm{i}}$ $13.5 \mathrm{eV}$. The energy of cold neutrals at the edge is taken to be $E_{0}=0.5 \mathrm{eV}$ in agreement with $\mathrm{H}_{\alpha}$ measurements [14] and a density $\mathrm{n}_{0}$, edge $=2 \times 10^{9} \mathrm{~cm}^{-3}$ is assumed.

Since EBT oporation is steady state in the toroidal mode, we emphasize for the most part steady-state results. However, such results are obtained by following the transport equations in time as described above until equilibrium is reaclied. This approach to equilibrium is illustrated for EBT I in Fig. 2a where radial profiles of electron density, ambipolar potential $\phi_{A}(r)=\int_{0}^{r} E_{r}(r) d r$, and ion and electron temperature are shown at time inlervals of 4 mgec until an approximate steady state is reached at $60 \mathrm{msec}$. Because the electric field is determined self-consistently, ion and electron particle fluxes are equal at each time step. Electron heat fluxes, on the other hand, are typically 10-40 times greater than ion heat fluxes.

The steady-state result is shown separately by the solid curves in Fig. 2b. The integrated electron density, $\int_{\mathrm{n}} \mathrm{dl} \approx 5 \times 10^{13} \mathrm{~cm}^{-2}$, is slightly higher than peak microwave interferometer measurements in the current experiment. Axial values of ion and electron temperatures 
are on the order of $100 \mathrm{eV}$ and $300 \mathrm{eV}$ respectively. Also, they are in good agreement with soft $x$-ray spectra [15] and ion charge-exchange measurements [16]. Particle lifetimes are on the order of $127 \mathrm{msec}$ on axis and $15 \mathrm{msec}$ at the edge averaging about $60 \mathrm{msec}$. The total stored energy in the toroidal component is about $58 \mathrm{~J}$ giving a gross energy confinement time of $5.3 \mathrm{msec}$. The total potential drop from the center of the plasma to the edge is on the order of $\mathrm{kT}_{\mathrm{e}} / \mathrm{e}$ and corresponds to an outward pointing radial field. Initial electric potential measurements made along an arc passing from the lower to the upper halves of the torus show a potential rise of about $\mathrm{kT}_{\mathrm{e}} / \mathrm{e}$ indicating an inward pointing electric field within the hot electron rings [17]. However, no exact information as to the plasma and ring horizontal location is obtained [17]. More recent observations made along a horizontal arc passing through the plasma suggest that the shape of the potential profile is strongly correlated to magnetic field errors in the experiment [7]. The effect of such field errors on transport rates is not included in the present calculations.

These comparisons between theory and experiment must be regarded as tentative because of the highly idealized nature of the calculations involved. In particular, a number of simplifying assumptions must be made in applying the diffusion rates in $\mathrm{Eq}$. (21) to both ions and electrons. These include neglecting effects of the hot electron rings and magnetic field errors on transport rates. However, it is encouraging that the present theory can be used to fit the experimental values of densities and temperatures. We should point out that for larger aspect ratio machines, such as EBT II, some of the theoretical assumptions 
(particularly with regard to geometry) would become more reasonable. In the current results, the direction and magnitude of the radial field are extremely sensitive to the relative difference between ion and electron diffusion rates. We conclude from ad hoc electric field calculations discussed in Section 4 that the gross plasma parameters are quite insensitive to this difference in diffusion rates and to the sign of the resulting field as long as thc radial field is of substantial magnitude.

\subsection{Extrapolation to EDT S}

We have computed similar solutions for parameters corresponding to EBT $S$ parameters with 24 mirror sectors and major radius $R_{T}=150 \mathrm{~cm}$. The plasma radius remains unchanged at $a=10 \mathrm{~cm}$, but the resonant magnetic field is increased to $B_{O}=9.25 \mathrm{kG}$ and total microwave power is increased to $200 \mathrm{KW}$ with $20 \%$ or $40 \mathrm{KW}$ deposited in the core plaslla. Luge noutral energy and density are taken as $\mathrm{E}_{0}=0.5 \mathrm{eV}$ and $\mathrm{n}_{0, \text { edge }}=5 \times 10^{9} \mathrm{~cm}^{-3}$, respecitvely. Tho eolid eurvos in Fig. 3 shnw results for a particular case which is not optimized. We note a factor of two increase in density, and $50 \%$ increase in ion temperature. Also particle containment time has doubled. In Section 5, self-consistent field calculations similar to thuse in Fig. 3 are used to evaluate confinement parameters for EBT $S$ over a range of plasma densities. Also the effect of supplementary ion heating is considered.

\section{AD HOC AMBIPOLAR ELECTRIC FIELD - ASSUMPTION}

The ad hoc ambipolar electric field assumption has previously been used in zero-dimensional or point models to compute steady-state solutions 
and the onset of thermal instability [18]. In this approximation, electron loss rates are assumed to be other than neoclassical and are set equal to the ion rates by ambipolarity. The electric potential is treated as a parameter.

Such an ad hoc field model is a limiting case of the self-consistent formulation given in Section 2 when the time step $\Delta t_{E}$ for solving Eq. (19) is set to zero. The electric field profile then remains fixed in time at its initial value $E_{r}(t=0)$ and becomes, in effect, a free parameter set by the initial conditions. Diffusion rates used are still the ambipolar rates from Eqs (17) and (21).

The dashed curves in Figs $2 b$ and. $3 b$ show steady state and ad hoc electric field solutions for EBT I and EBT S, respectively. For the ad hoc field cases we have chosen a cubic potential profile and assumed a potential rise of $175 \mathrm{~V}$ from the axis to the plasma edge. We note that while the selfconsistent and ad hoc electric field profiles are quite different, there are only minor differences between the two cases in the density and temperature profiles.

The resulting particle fluxes for the EBT I calculations are shown in Fig. 4. In the ad hoc electric field result (dashed curves), the negative electric field causes an inward flux of ions and an outward flux of electrons. The maximum ion flux occurs at $\mathrm{r} / \mathrm{a} \approx 0.25$ where there is cancellation of poloidal drifts for ions. In the self-consistent case, a positive electric field forms to decrease the outward flux of electrons and increase the ion flux electrostatically giving a resultant outward flux (solid line) which is the same for both species. 


\section{EFFECT OF VARIATION IN DISCHARGE CONDITIONS}

\subsection{Neutral Gas Density}

Effects of the edge neutral density on steady-state solutions for EBT $S$ are illustrated in this section using the self-consistent electric field model developed in Section 2. For $R_{T}=1.5 \mathrm{~m}$ and a fixed microwave power of $40 \mathrm{~kW}$ deposited in the toroidal component, we consider the scaling of discharge parameters with density. In Fig. 5, the peak steadystate ion temperature is plotted versus the radially averaged electron density, $\bar{n}=\frac{1}{a} \int_{0}^{a} e^{d r}$, as the edge neutral density is varied between 3.5 . and $6 \times 10^{9} \mathrm{~cm}^{-3}$. The points in this figure represent actual stable, steady-state solutions obtained with the self-consistent field model. Also plotted are the gross energy containment time, $\tau_{E}=\frac{2 \pi R_{T}}{P_{\text {core }}} \int_{0}^{a}\left(\frac{3}{2} n k T e+\right.$ $\left.\frac{3}{2} \mathrm{nkT}_{\mathrm{i}}\right) 2 \pi \mathrm{r} \mathrm{dr}$, and the $\overline{\mathrm{n}} \tau_{\mathrm{E}}$ product. Line average plasma densities $\overline{\mathrm{n}}$ range from $3 \times 10^{12}$ to $8 \times 10^{12} \mathrm{~cm}^{-3}$ with peak ion temperatures $100 \mathrm{eV} \leqslant$ $\mathrm{kT}_{i} \leqslant 160 \mathrm{eV}$ and energy confinement times $3 \mathrm{msec} \leqslant \tau_{E} \leqslant 7 \mathrm{msec}$. The resulting values of $\bar{n} \tau_{E}$ vary between 1.0 and $6.0 \times 10^{10} \mathrm{~cm}^{-3} \mathrm{sec}$. The selfconsistent potential drop between the plasma interior and edge, e $\phi_{A}$, is on the order of the peak electron temperature $\mathrm{kT}$ which varies from 400 to $700 \mathrm{eV}$. Error bars should be placed on these results principally due to uncertainty in the electric field calculation. We show in Section 5.3 for example that enhanced electron collisionality can reverse the sign of the electric field. Also the ad hoc electric field solutions in Section 4 for potential profiles similar to those observed in the EBT-I experiment suggest that errors on the order of $20 \%$ might not be unreasonable. 


\subsection{Supplementary Ion Heating}

To assess the effect of neutral beam injection power on the development of EBT discharges, we include an additional energy source on the right-hand side of the ion energy balance, Eq. (18b). This source has the form

$$
Q_{b}=C_{i} \frac{P_{b}}{2 \pi^{2} a^{2} R_{T}} H(r)
$$

where $P_{b}$ is the beam power, $G_{i}$ is the fraction of the total energy deposited in the ion component, and $H(r)$ is the radial heat deposition profile, which for simplicity we take to be parabolic. For a beam energy of $10 \mathrm{keV}, G_{i} \approx 1$ so that the beam energy is absorbed almost entirely by the ion component. Thus, no additional heat source has been added to the electron energy balance, Eq. (18c). Since the cross section for charge exchange of $10 \mathrm{keV}$ neutral hydrogen is an order of magnitude larger than that for ionization, no additional particle source term is included in the particle balance, Eq. (18a).

A typical result for EBT $S$ is shown in Fig. 6 with $P_{b}=10 \mathrm{~kW}$ and $\mathrm{n}_{\mathrm{o} \text {,edge }}=5 \times 10^{9} \mathrm{~cm}^{-3}$. Comparing results in Figs 3 and 6 , we notice that the ion temperature increases by about $25 \mathrm{eV}$ with $10 \mathrm{~kW}$ of beam power. The ambipolar potential and electron temperature also increase in Fig. 6 .

\subsection{Increased Electron Collisionality Due to Microwave Heating}

One possible explanation for the experimentally observed inward pointing radial electric field in EBT $I$ is that microwave heating provides an additional scattering mechanism for electrons which increases their effective collisionality. If we denote the resulting effective collision frequency for electrons by $v_{\mathrm{RF}}$ and assume that microwave and coulomb 
collisions have qualitatively similar effects on neoclassical diffusion rates, then Eq. (21) shows that for $\nu_{R F} \gg \Omega_{e}$, electron confinement is improved by this mechanism. The physical picture is that multiple microwave scatterings prevent electrons from completing a single particle drift orbit, thereby reducing the neoclassical diffusion rate. Or equivalently, electrons which scatter into the neoclassical loss region $\left(\Omega_{e} \approx 0\right)$ do not have time to drift out of the machine before another microwave collision removes them from the loss region. For $\nu_{\mathrm{RF}} \gtrsim$ $\nu_{00} \sqrt{m_{i} / m_{c}} \approx 10^{6} \mathrm{sec}^{-1}$, electrons become better confined than ions, and a radially inward pointing ambipolar field results. By comparison, in EBT I, the bounce frequency for $350 \mathrm{eV}$ electrons is about $\nu_{b} \approx 2 \times 10^{7}$ $\sec ^{-1}$ and the heating rate for electrons in a $30 \mathrm{~V} / \mathrm{cm}$ microwave electric field is on the order of $10^{7} \mathrm{eV} / \mathrm{sec}[11]$.

To illustrate the effect of such enhanced electron collisionality, we have repeated the calculation of Fig. 3 for EBT $S$ with an electron collision frequency $\nu_{e}=\nu_{e n}+\nu_{e e}+\nu_{\theta i}+\nu_{R F}$ where $\nu_{R F}=8 \times 10^{6}$ sec $^{-1}$. For $\mathrm{n}_{0, \text { edge }}=1 . \mathrm{b} \times 10^{9} \mathrm{~cm}^{-3}$ and $10 \%$ of the microwave power absorbed by toroidal electrons, the steady-state result is shown by the solid curves in Fig. 7. The observed potential rise, $\Delta \phi_{\mathrm{A}} \approx 415 \mathrm{~V}$ indicates an inward pointing electric field as observed in the EBT I experiment. The ambipolar potential varies with the temperature of the more rapidly diffusing species, in this case the ions. Hence, $10 \mathrm{~kW}$ of supplementary ion heating leads to a larger ambipolar potential shown by the dashed curves in Fig. 7 , and an improved heating efficiency as indicated by the $50 \mathrm{eV}$ increase in ion temperature. This is about twice the temperature rise observed in the positive field case of Fig. 6 for the same power input. 
A more rigorous treatment of the effect of microwave resonance on neoclassical diffusion of electrons requires including a Fokker-Plank collision term in the drift kinetic equation to model microwave scattering of electrons in the calculation of neoclassical transport rates.

\section{CONCLUSION}

The calculations reported here should be considered as a further step in the solution of a very complex problem. It has been shown that a selfconsistent electric field can be calculated numerically at each time step in a radial transport simulation for the core plasma in EBT. Timedependent solutions approach stable equilibria when enhanced diffusion is included at low collisionalities to limit arbitrarily large electric fields and steep gradients. The calculations show potentials inside the plasma which are generally positive with respect to those at the edge and with magnitude comparable to $\mathrm{kT}_{\mathrm{e}} / \mathrm{e}$. An ad hoc electric field model appears to give reasonable results for density and temperature profiles although radial fluxes of ions and electrons are not necessarily equal. Self-consistent calculations for EBT $S$ with a major radius of $1.50 \mathrm{~m}$ and $40 \mathrm{~kW}$ of microwave power absorbed in the core plasma predict $\overline{\mathrm{n}}_{\mathrm{E}} \sim 6 \times 10^{10} \mathrm{sec} \mathrm{cm}^{-3}$ and $\mathrm{kT}_{i} \sim 150 \mathrm{eV}$ for line average densities of

$8 \times 10^{12} \mathrm{~cm}^{-3}$. Supplementary ion heating increases ion temperature; however, the magnitude of the increase is dominated by the effect on the ambipolar field. Finally, artificially enhanced electron collisionality can cause inward pointing radial electric fields. One possible mechanism for such enhanced collisionality may be the increased scattering of electrons due to microwave resonances. In order to obtain a more accurate 
description of steady-state plasmas in EBT, this work should be extended to include effects of the hot electron annulus on the ambipolar potential and the effects of magnetic field errors and drift waves on transport rates.

\section{ACKNOWLEDGEMENTS}

The authors wish to thank R. A. Dandl, N. H. Lazar, G. E. Guest, D. B. Batchelor, D. A. Spong, and the entire ORNL EBT experimental group for many lielpful discusstons. 


\section{REFERENCES}

1. Hogan, J. T., Methods in Computational Physics 16 , Chapter 4, Academic Press, New York (1976).

2. Hazeltine, R. D., Plasma Phys. 15 (1973) 77.

3. Kovrizhnykh, L. M., Sov. Phys.-JETP 29 (1969) 475; and Preprint FIAN, No. 128, Moscow (1969).

4. Spong, D. A., Harris, E. G., and Hedrick, C. L., "Neoclassical Ion Transport Coefficients for the ELMO Bumpy Torus Device," paper presented at the 18th Annual Meeting, Div. of Plasma Phys. of the American Physical Society, San Francisco, California, November 15-19, 1976;

Bu11. Am. Phys. Soc. 21 (1976) 1069, paper 3C-4.

5. Hedrick, C. L., Jaeger, E. F., Spong, D. A., Guest, G. E., Krall, N. A., McBride, J. B., and Stuart, G. W., CRNL/TM-5490 (1977), Oak Ridge Nationa1 Laboratory, Oak Ridge, Tennessee, submitted to Nucl. Fusion.

6. Ikegami, H., and Dandl, R. A., EBT Group, Oak Ridge National Laboratory, Oak Ridge, Tennessee, Technical Memo \#14 (1974).

7. : Quon, B. H., Dandl, R. A., EBT Group, Oak Ridge National Laboratory, Oak Ridge, Tennessee, Technical Memo \#77/48-49 (1977).

8. Batchelor, D. B., Hedrick, L., Theory Section, Oak Ridge National Laboratory, Oak Ridge, Tennessee, Technical Memo \#77/16 (1977) .

9. McBride, J. B., Internal Report, LAPS-I-6 (1976).

10. Warden, E. S., Moos, H. W., Lazar, N. H., ORNL/TM-5899, Oak Ridge National Laboratory, Oak Ridge, l'ennessee (1977).

11. Eldridge, 0., Phys. Fluids 15 (1972) 676.

12. Hogan, J. T., Clarke, J. F., J. Nucl. Mater. 53 (1974) 1; Munro, J. K., Hogan, J. T., Howe, H. C., and Arnurius, D. ^., ORNL/TM-526?, Oak Ridge National Laboratory, Oak Ridge, Tennessee (1976). 
13. Richtmyer, R. D., Morton, K. W., Difference Methods for Initial Value Problems, Interscience, New York (1967).

14. Cobble, J. A., EBT Group, Oak Ridge National Laboratory, Oak Ridge, Tennessee, Technical Memo \#77/43 (1977).

15. Haste, G. R., EBT Group, Oak Ridge National Laboratory, Oak Ridge, Tennessee, Technical Memo (1976).

16. Baity, F. W., Quon, B. H., EBT Group, Oak Ridge National Laboratory, Oak Ridge, Tennessee, Technical Memo \#76/41 (1976).

17. Colestock, P. L., EBT Group, Oak Ridge National Laboratory, Oak Ridge, Tennessee, Technical Memo \#77/47 (1977).

18. Guest, G. E., Hedrick, C. L., Harris, E. G., Oak Ridge National Laboratory, Oak Ridge, Tennessee, private communication. 


$$
\text { ORNL-DWG 77-12491 }
$$

\section{TOROIDAL COORDINATE SYSTEM}

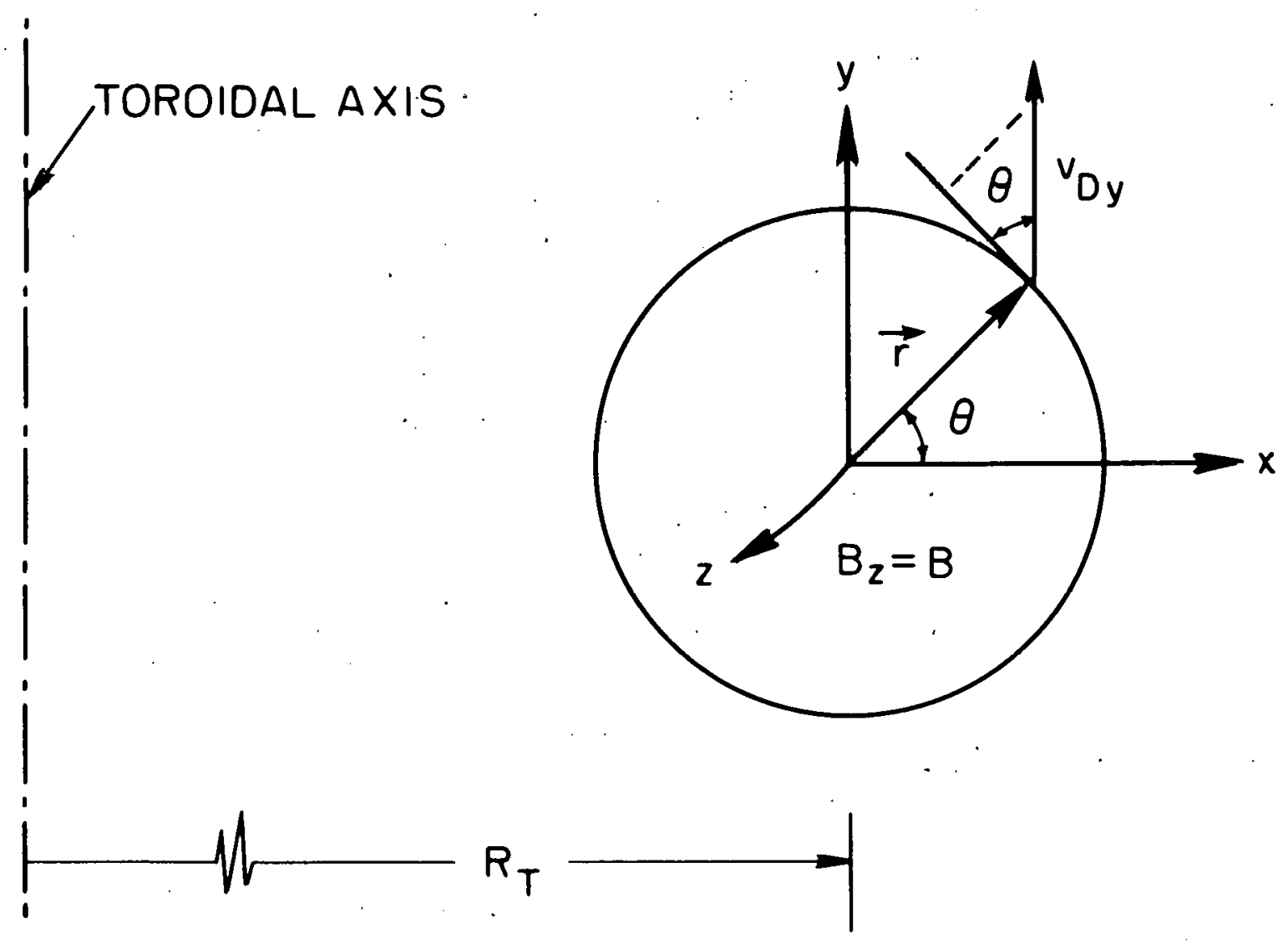

Fig. 1. Toroidal coordinate system. 
ORNL/DWG/FED $\cdot \mathbf{7 7 4 3 0}$

NUMERICÁL RESULTS FOR EBT I

(0) $\left(\times 10^{12}\right.$
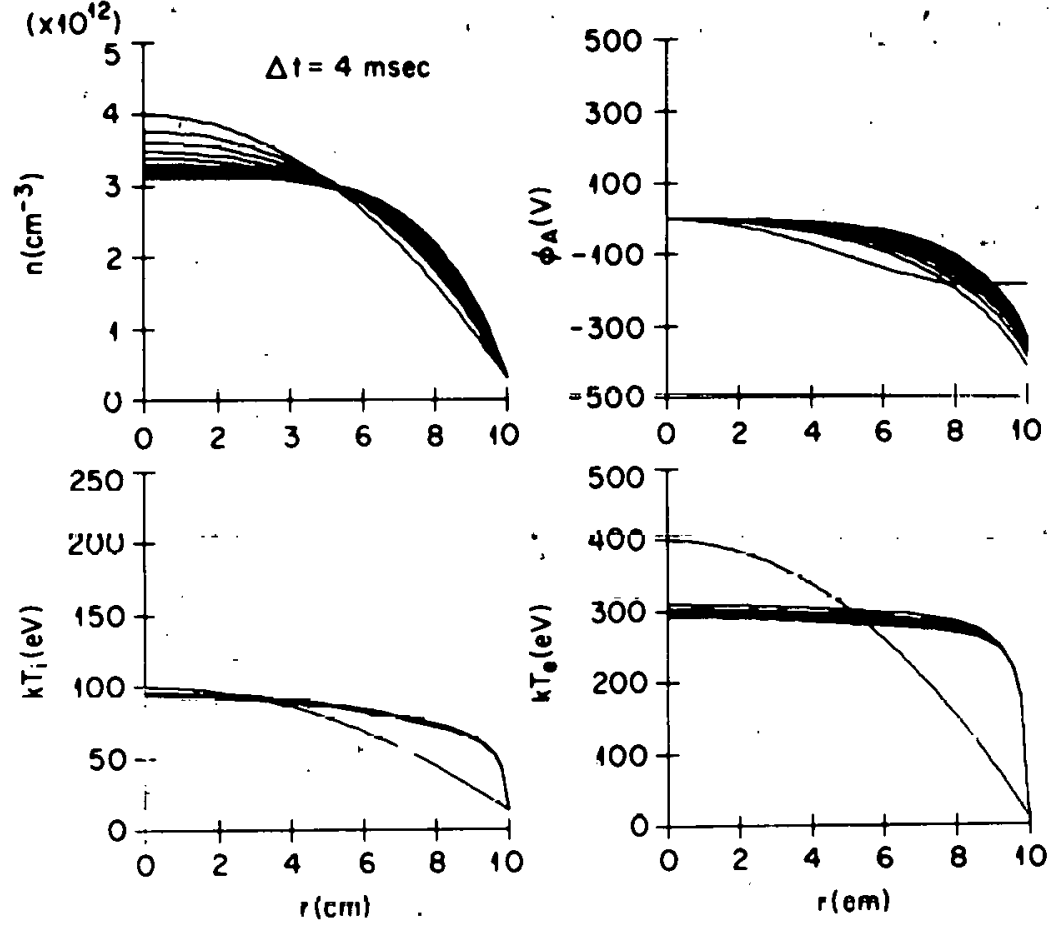

(b) $\quad\left(x+n^{12}\right)$
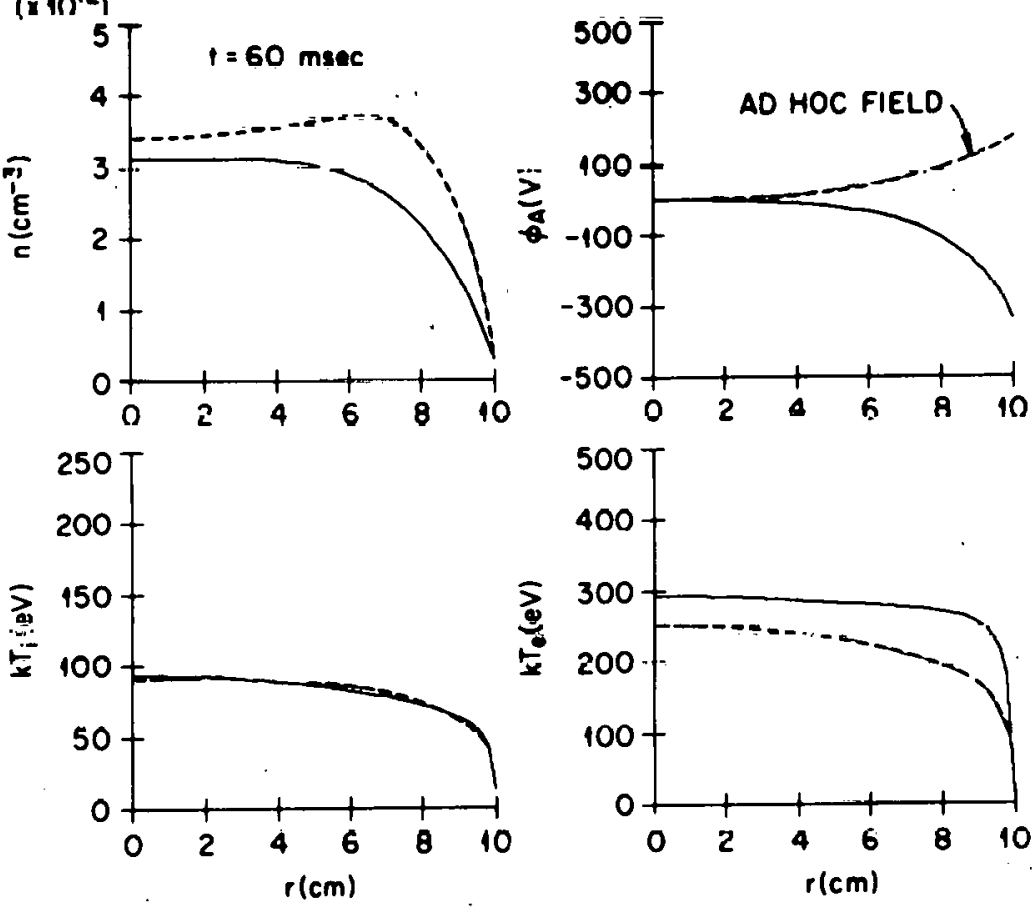

Fig. 2. Numerical results for EBT,I. 
ORNL/OWG/FED .77586

\section{NUMERICAL RESULTS FOR EBT S}

(0)
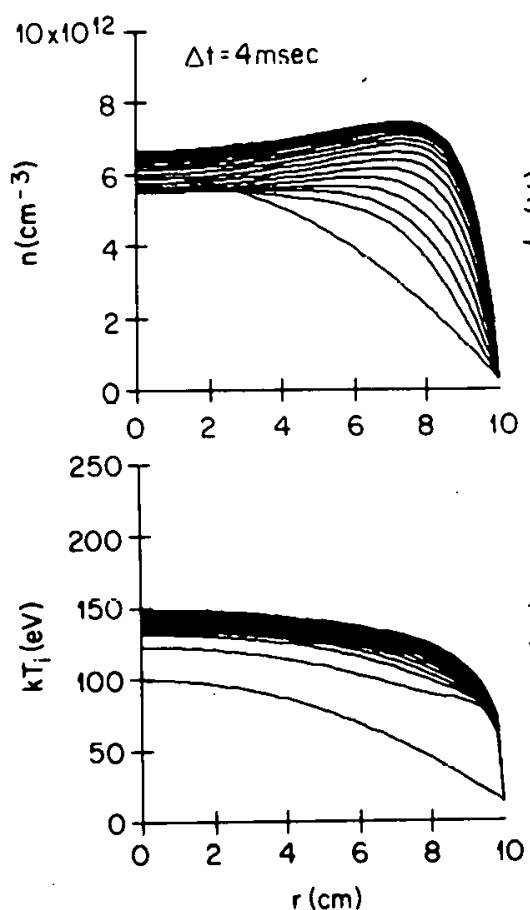

(b)
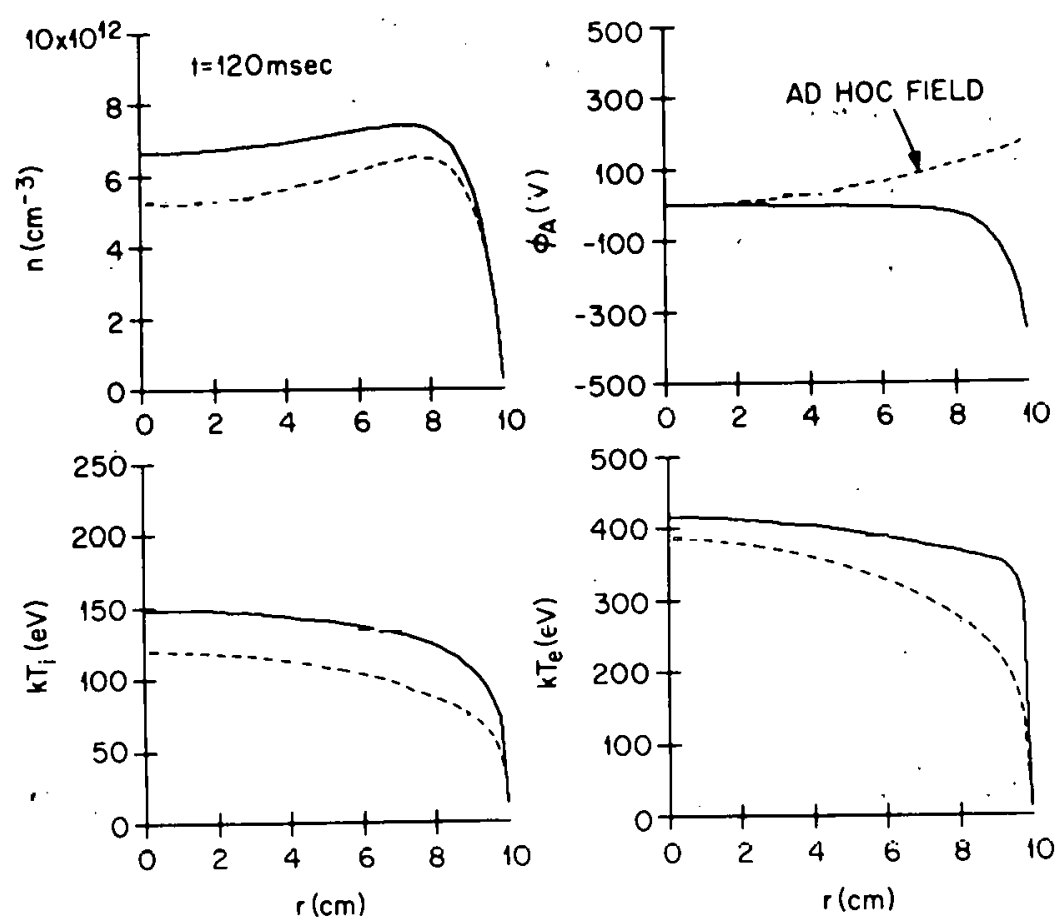

Fig. 3. Numerical results for EBT S. 


$$
\text { ORNL-DWG } 77-12490
$$

\section{CHARGED PARTICLE FLUX PROFILES}

AT $60 \mathrm{msec}$ FOR EBT-I

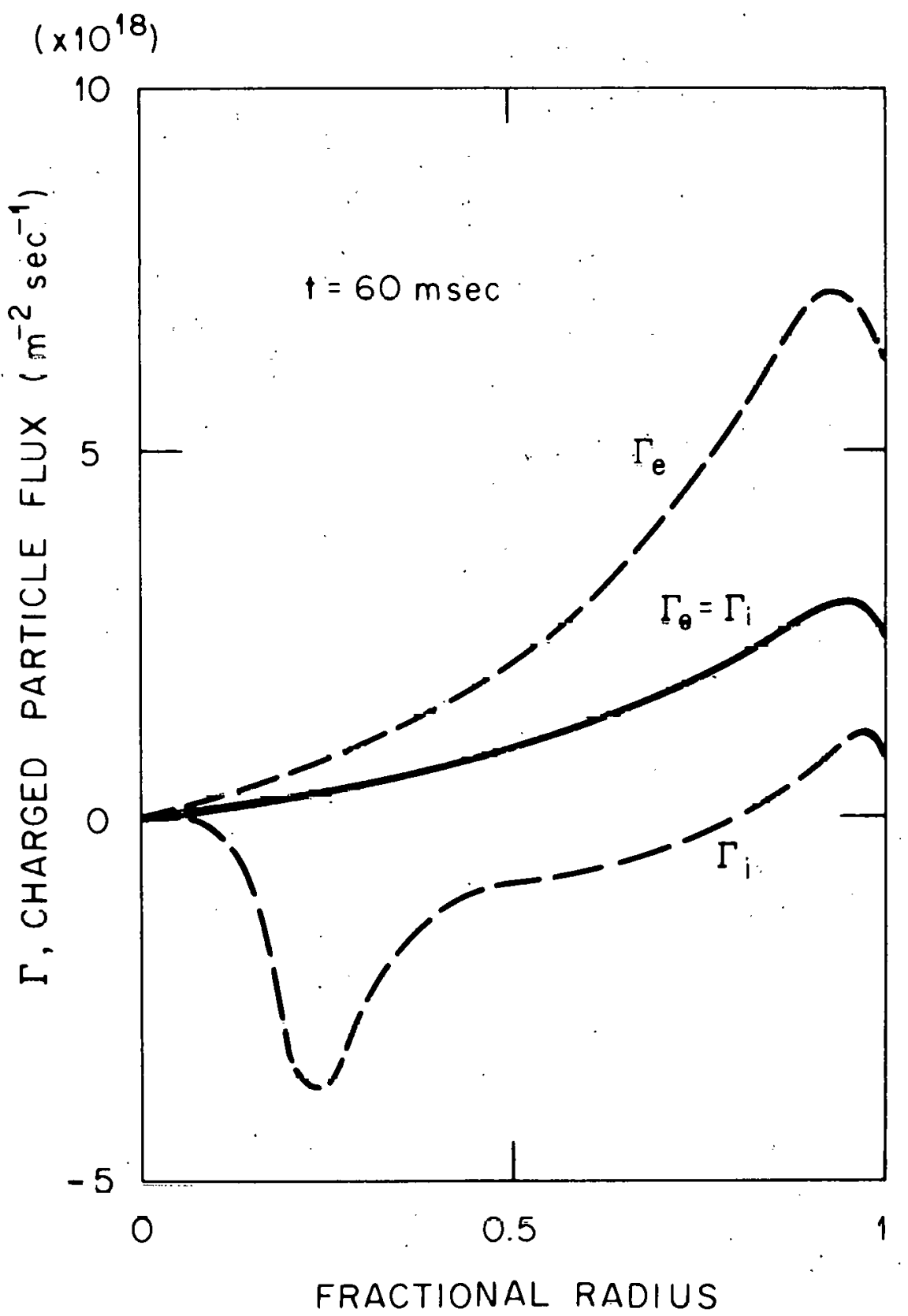

Fig. 4. Charged particle flux profiles for the discharge of Fig. 2. 
ORNL/DWG/FED-77583

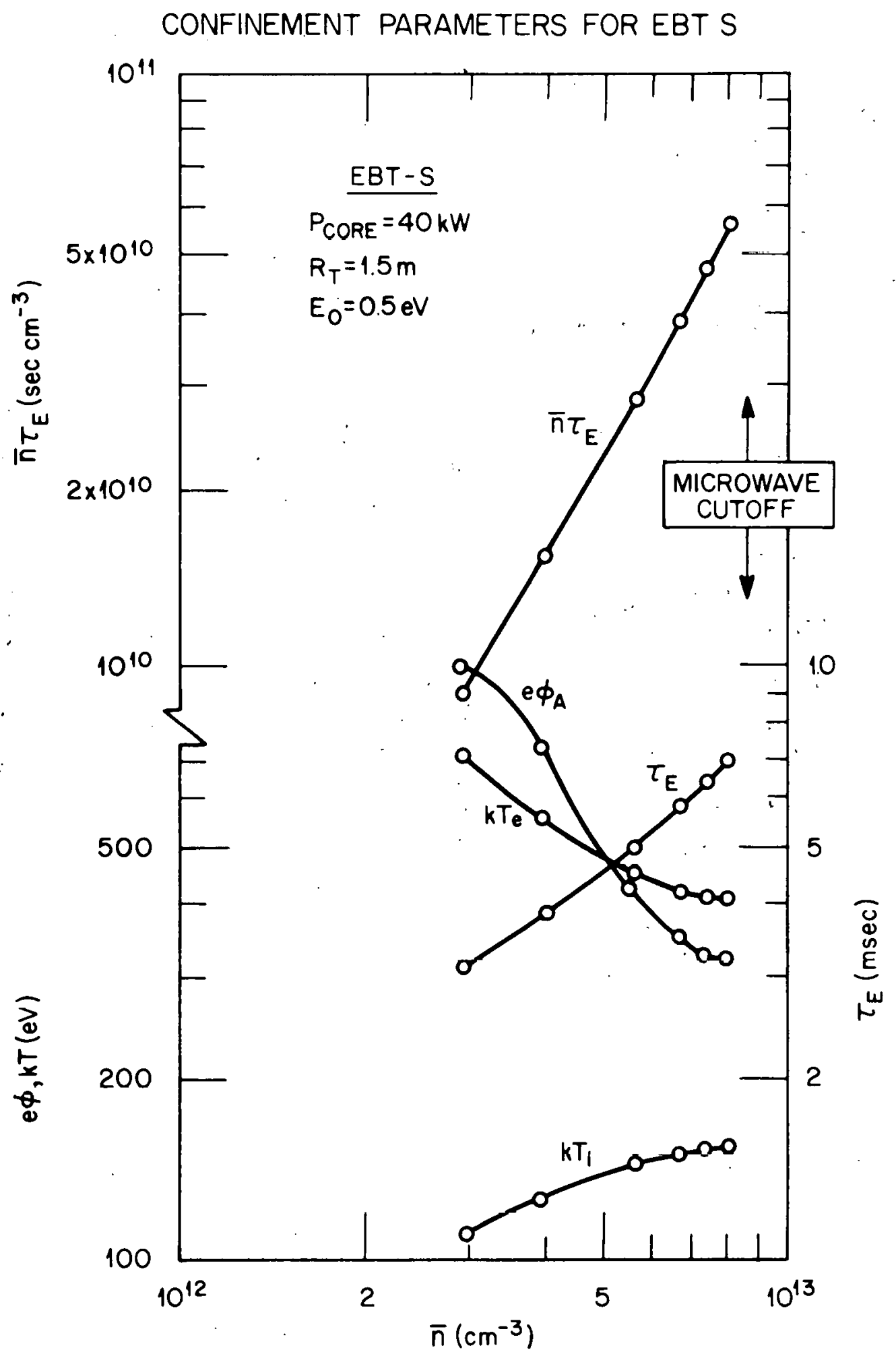

Fig. 5. Confinement parameters for LDT $S$. 
ORNL/DWG/FED - 77584

\section{EBT S WITH 10kW OF SUPPLEMENTARY ION HEATING}
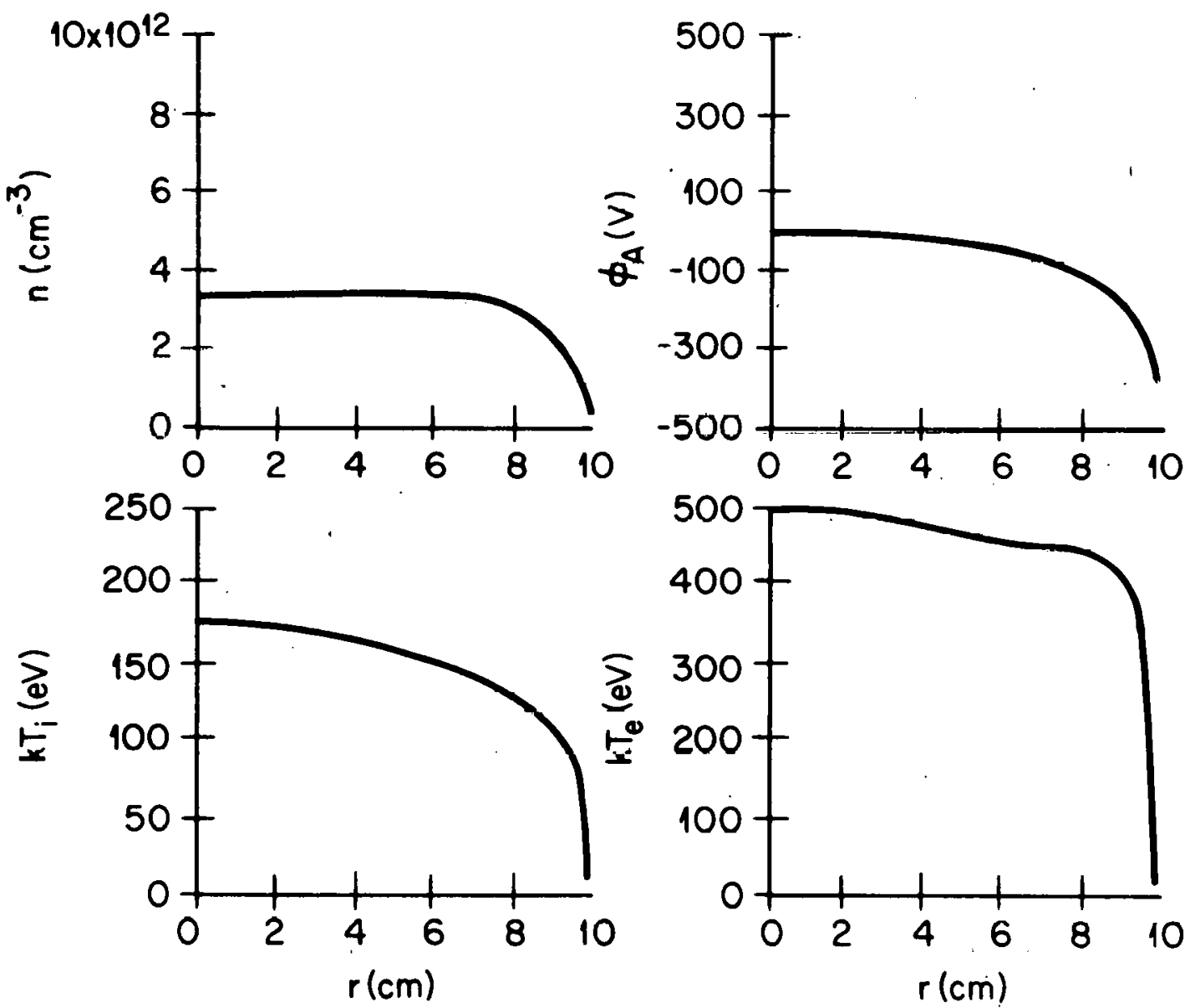

Fig. 6. Steady-state result for EBT $S$ with supplementary ion heating. 
ORNL/DWG/FED $\cdot 77585$

\section{EBT S WITH ARTIFICALLY ENHANCED ELECTRON COLLISIONALITY}
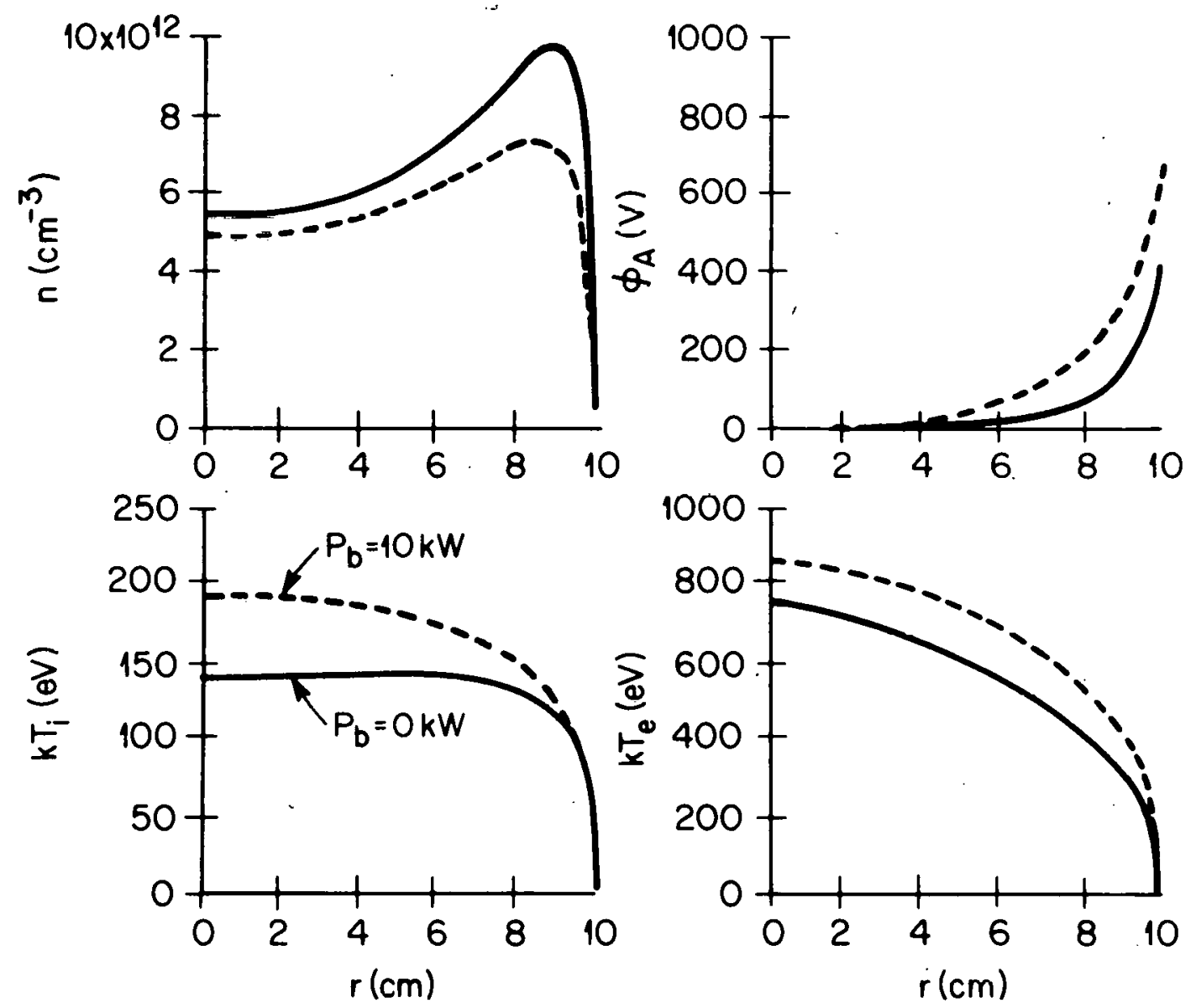

Fig. 7. Steady-state results for EBT $S$ with and without ion heating for artificially enhanced electron collisionality. 
THIS PAGE

WAS INTENTIONALLY

LEFT BLANK 
INTERNAL DISTRIBUTION

ORNL/TM-6013,

1. J. D. Callen

2. J. F. Clarke

3. R. A. Dory

4. G. G. Kelley

5. O. B. Morgan

6. M. W. Rosentha1

7-31. E. F. Jaeger

32-34. Laboratory Records Department

35. Laboratory Records, ORNL - RC

36. Y-12 Document Reference Section

37-38. Central Research Library

39. Fusion Energy Division Library

40. Fusion Energy Division Reports Office

41. ORNL Patent Office

EXTERNAL DISTRIBUTION

42. Plasma Physics Library, Plasma Physics Laboratory, Princeton Univ., Forrestal Campus, P.0. Box 451, Princeton, NJ 08540

43. Controlled Thermonuclear Research Library, Lawrence Livermore Laboratory, P.0. Box 808, Livermore, CA 94550

44. Q Division Library, Los Alamos Scientific Laboratory, P.0. Box 1663, Los Alamos, NM 87544

45. Controlled Thermonuclear Research Library, c/o Weston M. Stacey, Jr., Argonne National Laboratory, 9700 S. Cass Ave., Argonne, IL 60439

46. CTR Computer Center, c/o Dr. John Killeen, Lawrence Livermore Laboratory, P.0. Box 808, Livermore, CA 94550

47. Librarian, Culham Laboratory, U.K. Atomic Energy Authority, Abingdon, Oxon, OX14 3DB, United Kingdom

48. Ruth Lengye, Bibliothek, Max-Planck Institut für Plasmaphysik, 8046 Garching bei München, Federal Republic of Germany

49. Library, Centre de Recherches en Physique des Plasmas, 21 Avenue des Bains, 1007, Lausanne, Switzerland,

50. A. M. Dupas, Documentation S.I.G.N., Départment de la Physique du Plasila et de la Fusion Controlée, Association EURATOM-CEA sur la Fusion, Centre d'Etudes Nucléaires, BP 85 Centre Du TRI 38041 Grenoble Cedex (France)

51. Bibliothèque, Service du Confinement des Plasmas, C.E.A., B.P. No. 6, 92, Fontenay-aux-Roses (Seine) France

52. Library, International Centre for Theoretical Physics, Trieste, Italy

53. Library, Laboratorio Gas Ionizzati, Frascati, Italy

54. V. E. Ivanov, Physical-Technical Institute of the Ukranian Academy of Sciences, Sukhumi, U.S.S.R.

55. L. M. Kovrizhnikh, Lebedev Institute of Physics, Academy of Sciences of the U.S.S.R., Leninsky Prospect 53, Moscow, U.S.S.R.

56. Prof. Dshumber G. Lominadze, Academy of Sciences of the Georgian SSR, 8 Dzerzhinski St., 38004, Tbilisi, U.S.S.R.

57. Library, Inst. for Plasma Physics, Nagoya Univ., Nagoya, Japan 464 
58. Library, FOM-Institut voor Plasma-Fysica, Rijnhuizen, Jutphaas, Netherlands

59. Plasma Physics Group, Department of Engineering Physics, Australian National University, P.0. Box 4, Canberra A.C.T. 2600, Australia

60. Thermonuclear Library, Japan Atomic Energy Research Institute, Tokai, Naka, Ibaraki, Japan

61. Dr. D. G. McAlees, Exxon Nuclear Co., Inc., Research \& Technology Laser Enrichment Department, 2955 George Washington Way, Richland, WA 99352

62. CTR Reading Room, c/o Prof. D. W. Kerst, Dept. of Physics, Sterling Hal1, Univ. of Wisconsin, Madison, WI 53706

63. CTR Reading Room, c/o Prof. I. B. Bernstein, Yale Univ., 200 Mason Laboratory, Dept. of Engineering \& Applied Science, New Haven, CT 06510

64. Center for Plasma Physics and Thermonuclear Research, c/o D. W. Ross, Physics Dept., Univ. of Texas, Austin, TX 78712

65. C'rR Reading Roum, C/o Prof. B. D. Fried, Physics Dept., Univ, of Cali fornia, Los Angeles, CA 90024

66. CTR Reading Room, c/o Prof. David C. Montgomery, Physics \& Astron= omy Dept., Univ. of Iowa, Iowa City, IA 52240

67. Magneto-Fluid-Dynamics Library, c/o Dr. Harold Grad, Courant Inst. of Math. Sci., New York Univ., 251 Mercer St., New York, NY 10012

68. CTR Reading Room, c/o Prof. Allan N. Kaufman, Physics Dept., Univ. of California, Berkeley, CA 94720

69. Dr. David A. Dingee, Fusion Programs, Battelle-Northwest, Battelle Bnulevard, Kichnländ, WA 99352

70. CTR Reading Room, c/o Prof. C. S. Liu, Dept. of Physics and Astronomy, Univ. of Maryland, College Park, MD 20742

71. CTR Reading Room, c/o Prof. T. Kammash, 103 Research $\Lambda$ dmin. Bldg., N. Campus, Univ. of Michigan, Ann Arbor, MI 48105

72. CTR Reading Room, c/o Dr. Ravi N. Sudan, Phillips Hall, Cornell Univ., Ithaca, NY 14850

73. Prof. Marshal1 N. Rosenbluth, Institute for Advanced Study, Princeton, NJ 08540

74. CTR Reading Room, c/o Prof. R. Cross, Plasma Research Lab., Columbia Univ., New York, NY 10027

75. CTR Reading Room, c/o Prof. Roy Gould, California Inst. of Tech., M.S. 116-81, Pasadena, CA 91125

76. Dr. Nicholas A. Kra11, Science Applications, Inc., P.0. Bux 2354, 1200 Prospect. St., La Julla, CA 92037

77. CTR Reading Room, c/o Dr. Jay P. Boris, Plasma Physics, Naval Research Laboratory, Washington, D.C. 20390

78. Profeasor $\Lambda$. Simon, Dept. nf Mechanical \& Aerospace Sciences, University of Rochester, Rochester, NY 1462\%

79. CTR Library, c/o Dr. Alan F. Haught, United Technologies Research Labs, East Hartford, CT 06108

80. Dr. H. K. Forsen, Exxon Nuclear Co., Inc., 777-106th Avenue, NE, $\mathrm{C}=000777$, Bellevue, WA 98009

81. Dr. George Vahala, Physics Dept., College of William \& Mary, Williamsburg, VA 23185

82. Dr. Robert E. Price, Division of Magnetic Fusion Energy, G-234, Department of Energy, Washington, DC 20545 
83. Dr. R. C. Davidson, Division of Magnetic Fusion Energy, G-234 Department of Energy, Washington, D.C. 20545

84. Dr. Oscar P. Manley, Division of Magnetic Fusion Energy, G-234, Department of Energy, Washington, D.C. 20545

85. Mr. E. E. Kintner, Division of Magnetic Fusion Energy, G-234, Department of Energy, Washington, D.C. 20545

86. Dr. L. D. Pearlstein, L-388, Lawrence Livermore Laboratory, P.0. Box 808, Livermore, CA 94550

87. Dr. J. P. Friedberg, Los Alamos Scientific Laboratory, Los Alamos, NM 87544

88. Dr. David J. Rose, Dept. of Nuclear Engineering, MIT, Cambridge, MA 02139

89. Dr. Gareth E. Guest, General Atomic Co., P.0. Box 81608, San Diego, CA 92138

90. Dr. Claude Mercier, Service du Theorie des Plasmas, Centre d'Etudes Nucleaires, Fontenay-aux-Roses (Seine) France

91. Dr. J. B. Taylor, Culham Laboratory, UKAEA, Abingdon, Oxon, 0X14 3DB, United Kingdom

92. Dr. D. Pfirsch, Institute for Plasma Physics, 8046 Garching bei München, Federal Republic of Germany

93. Dr. V. D. Shafranov, I. V. Kurchatov Inst. of Atomic Energy, 46 Ulitsa Kurchatova, P.O. Box 3402, Moscow, U.S.S.R.

94. Dr. A. Rogister, Institute for Plasma Physics, KFA, Postfach 1913, D-5170, Jülich 1, Federal Republic of Germany

95. Dr. J. G. Cordey, Culham Laboratory, UKAEA, Abingdon, Oxon, 0X14 3DB, United Kingdom

96. Dr. David Baldwin, L-388, Lawrence Livermore Lab., P.0. Box 808, Livermore, CA 94550

97. CTR Reading Room, c/o Prof. Bruno Coppi, Dept. of Physics, MIT, Cambridge, MA 02138

98. Dr. Harold P. Furth, Princeton Plasma Physics Lab., Princeton Univ., P.0. Box 451, Princeton, NJ 08540

99. Dr. Paul H. Rutherford, Princeton Plasma Physics Lab., Princeton Univ., P.0. Box 451, Princeton, NJ 08540

100. Research \& Technical Support Div., Oak Ridge Operations, Department of Energy, P. O. Box E, Oak Ridge, TN 37830

101-127. Tech. Information Center, P. 0. Box 62, Oak Ridge, TN 37830 